\title{
Self-efficacy and future anxiety among students of nursing and education colleges of Helwan University
}

\author{
Samah Rabei ${ }^{1 *}$, Sorayia Ramadan² and Nahla Abdallah
}

\begin{abstract}
Background: Self-efficacy and future anxiety affect students' performance. A relation between both is suggested and needs to be investigated. The aim of this study is designed to assess self-efficacy, future anxiety among Helwan University students, and the relation between them.

Results: Ten percent of colleges' students were subjected to self-efficacy scale and future anxiety scales. Future anxiety is significantly related to self-efficacy. Self-efficacy is significantly higher in the college of nursing. There is a significant increase in self-efficacy in the 1st grade, while there is a significant increase in future anxiety in the 4th grade.

Conclusion: There is a negative significant correlation between age and self-efficacy, while there is a positive significant correlation between age and future anxiety.
\end{abstract}

\section{Background}

Goal realization is composed of four processes: selfobservation, self-evaluation, self ${ }^{-}$reaction, and selfefficacy [1]. Self-efficacy can be defined as individuals' beliefs about their capabilities to produce designated levels of performance that influence over events affecting their lives. The beliefs determine how people feel, think, motivate themselves, and behave, which are added to the production of diverse effects through cognitive, motivation, and affective processes [2]. According to Tirana 2013, the four sources of information that individual employs to judge their efficacy are performance outcomes (performance accomplishments), vicarious experiences, verbal persuasion, and physiological feedback (emotional arousal). These components help individuals determine if they believe they have the capability to accomplish specific tasks [3].

The root meaning of the word anxiety is "to vex or trouble"; in either the presence or absence of

\footnotetext{
* Correspondence: samahrabe@yahoo.com

${ }^{1}$ Helwan University, Ain Helwan, Cairo, Egypt

Full list of author information is available at the end of the article
}

psychological stress, anxiety can create feelings of fear, worry, uneasiness, and dread [4]. Anxiety can be defined as a psychological and physiological state characterized by physical, emotional, cognitive, and behavioral components. It is considered to be a normal response to stress. It may help an individual to cope with the demands of life, but in excess, it may be considered as an anxiety disorder [5]. Future anxiety can be defined as a state of apprehension, uncertainty, fear, worry, and concern of unfavorable changes in a more remote personal future. In an extreme case, this would be a threat (panic) that something really ${ }^{34}$ catastrophic may happen to a person [6]. People who suffer from future anxiety have some characteristics as decremented efficiency in experimental tasks [7]. Negative effects of future anxiety are as follows: on the cognitive level, El-Meshekhy [8] refers that future anxiety may lead to [1] an impairment of the subjective expectancy of positive outcomes of one's own actions, so lessening the probability of success and [2] an attention concentration on the present time and events; or escapism into the known past, both mechanisms limiting the temporal space of an individual. On the

\section{Springer Open}

(- The Author(s). 2020 Open Access This article is licensed under a Creative Commons Attribution 4.0 International License, which permits use, sharing, adaptation, distribution and reproduction in any medium or format, as long as you give appropriate credit to the original author(s) and the source, provide a link to the Creative Commons licence, and indicate if changes were made. The images or other third party material in this article are included in the article's Creative Commons licence, unless indicated otherwise in a credit line to the material. If material is not included in the article's Creative Commons licence and your intended use is not permitted by statutory regulation or exceeds the permitted use, you will need to obtain permission directly from the copyright holder. To view a copy of this licence, visit http://creativecommons.org/licenses/by/4.0/. 
behavioral level, Cassady [9] refers that future anxiety may lead to [1] a passive waiting of what can occur [2]; withdrawal from risky, open, and constructive activities [3]; keeping to routine ways and tested methods of dealing with situations encountered in life [4]; undertaking preventive activities in order to preserve the status quo rather than taking risks to increase present opportunities [5]; using different regressive-type defense mechanisms such as accusation, rationalization, or repression, in order to reduce the negative state; and [6] the use of social relationships to help secure one's own future.

A negative correlation is found between social anxiety and self-efficacy by Al Rauwaili et al. [10]. Self-efficacy promotes resilience unlike anxiety which impairs resilience that affects well-being as proven by Wylds [11].

\section{Methods}

A) Setting: in the College of Nursing and College of Education, Helwan University

B) Subject: $10 \%$ of the total number of university colleges chosen according to random selection in the College of Nursing and College of Education (represent practical and theoretical colleges).

C) Timetable: between June and December 2016

D) Tools for data collection:

- A structured questionnaire for socio-demographic variables

- Self-efficacy scale [12]: 32 statements in 4 main items (performance accomplishment, vicarious experiences, persuasion, emotional arousal). These scores were converted into a percent score by multiplying the score by 100 and dividing it by maximum possible score

- Future anxiety scale [13]: 40 statements in 4 main items (fear of future problems, pessimism, future worry thinking, death anxiety). These scores were converted into a percent score by multiplying the score by 100 and dividing it by maximum possible score

E) Statistical analysis was done using SPSS version 20

Table 1 Demographic data of the studied group

\begin{tabular}{llll}
\hline & & \multicolumn{2}{l}{ Total "n=481" } \\
\cline { 3 - 4 } & & No. & $\%$ \\
\hline Age & $<20$ & 289 & 60.1 \\
\multirow{2}{*}{ Grade } & $>20$ & 192 & 39.9 \\
& 1st year & 289 & 60.1 \\
\multirow{2}{*}{ College } & 4th year & 192 & 39.9 \\
& Education & 411 & 87.2 \\
& Nursing & 70 & 12.8 \\
\hline
\end{tabular}

Table 2 Self-efficacy among students

\begin{tabular}{llll}
\hline Self-efficacy scale & & No. & $\%$ \\
\hline Performance accomplishment & Sometimes & 5 & 1.0 \\
& Not sure & 133 & 27.7 \\
& Much & 296 & 61.5 \\
& Very much & 47 & 9.8 \\
Vicarious experiences & Sometimes & 6 & 1.2 \\
& Not sure & 134 & 27.9 \\
& Much & 297 & 61.7 \\
Persuasion & Very much & 44 & 9.1 \\
& Sometimes & 40 & 8.3 \\
& Not sure & 278 & 57.8 \\
& Much & 135 & 28.1 \\
& Very much & 28 & 5.8 \\
Emotional arousal & Sometimes & 16 & 3.3 \\
& Not sure & 144 & 29.9 \\
& Much & 266 & 55.3 \\
& Very much & 55 & 11.4 \\
& Total & 481 & 100.0 \\
\hline & & &
\end{tabular}

Table 3 future anxiety among students

\begin{tabular}{llll}
\hline Future anxiety scale & & No. & $\%$ \\
\hline The fear of future problems & Strongly disagree & 3 & .6 \\
& Disagree & 103 & 21.4 \\
& Neutral & 258 & 53.6 \\
& Agree & 111 & 23.1 \\
& Strongly agree & 6 & 1.2 \\
Pessimism about the future & Strongly disagree & 1 & .2 \\
& Disagree & 70 & 14.6 \\
& Neutral & 292 & 60.7 \\
& Agree & 116 & 24.1 \\
& Strongly agree & 2 & .4 \\
Worry thinking about the future & Strongly disagree & 35 & 7.3 \\
& Neutral & 349 & 72.6 \\
& Agree & 93 & 19.3 \\
& Strongly agree & 4 & .8 \\
& Strongly disagree & 4 & .8 \\
Death anxiety & Disagree & 70 & 14.6 \\
& Neutral & 272 & 56.5 \\
& Agree & 125 & 26.0 \\
& Strongly agree & 10 & 2.1 \\
& Total & 481 & 100.0 \\
\hline
\end{tabular}


Table 4 Comparing future anxiety levels as regards self-efficacy levels

\begin{tabular}{|c|c|c|c|c|c|c|c|c|c|}
\hline \multirow{3}{*}{$\begin{array}{l}\text { Future } \\
\text { anxiety } \\
\text { scale } \\
\text { category }\end{array}$} & \multicolumn{8}{|c|}{ Self-efficacy scale category } & \multirow[t]{3}{*}{ Total } \\
\hline & \multicolumn{2}{|l|}{ Low } & \multicolumn{2}{|l|}{ Mild } & \multicolumn{2}{|c|}{ Moderate } & \multicolumn{2}{|c|}{ High } & \\
\hline & No. & $\%$ & No. & $\%$ & No. & $\%$ & No. & $\%$ & \\
\hline Low & 0 & 0.0 & 10 & 4.5 & 17 & 27.0 & 3 & 100.0 & 30 \\
\hline Mild & 26 & 13.3 & 90 & 40.9 & 45 & 71.4 & 0 & 0.0 & 161 \\
\hline Moderate & 133 & 68.2 & 120 & 54.5 & 1 & 1.6 & 0 & 0.0 & 254 \\
\hline High & 36 & 18.5 & 0 & 0.0 & 0 & 0.0 & 0 & 0.0 & 36 \\
\hline Total & \multicolumn{2}{|l|}{195} & \multicolumn{2}{|l|}{220} & \multicolumn{2}{|l|}{63} & \multicolumn{2}{|l|}{3} & \\
\hline$x^{2}$ & \multicolumn{8}{|l|}{26.85} & \\
\hline$p$ & \multicolumn{8}{|c|}{$0.001^{*}$} & \\
\hline
\end{tabular}

\section{Ethical considerations}

Informed written consent was taken from parents before participation. The aim and procedures of the study were explained to them. There was no moral or financial pressure laid on them to participate. Confidentiality was assured. The results of the study are planned to a scientific publication that serves and improves policies and plans affecting their quality of life.

\section{Results}

Table 1 shows that $60 \%$ of the study sample participants are below the age of 20 and in the first year grade. Also, $87.2 \%$ of the study sample participants are in the College of Education.

Table 2 shows that almost $60 \%$ of study sample participants are (Much Sure) of their self-efficacy performance accomplishment and vicarious experiences, persuasion, and emotional arousal.

Table 3 shows that more than half of the study sample participants are (neutral) as regards their future anxiety: fear of future problems, $60 \%$ are (neutral) as regards pessimism, $72 \%$ are (neutral) as regards future worry thinking, and $56 \%$ are (neutral) as regards fear of death.

In Table 4, by comparing future anxiety levels as regards self-efficacy levels using chi-square test; it is clear that all participants with high self-efficacy (no. $=3$, $100 \%$ ) has low anxiety level; participants with moderate self-efficacy: $27 \%$ has low anxiety and $71.4 \%$ has low anxiety.
These findings have high statistical significance as per chi-square test $(p$ value +0.001$)$

In Table 5, by comparing college type as regards both future anxiety and self-efficacy crude scores using Student $t$ test: it is clear that the mean score of self-efficacy and future anxiety of students in the College of Education is lower than students in the College of Nursing.

These findings have high statistical significance as per Student's $t$ test ( $p$ value +0.001 )

In Table 6 , by comparing the 1st and 4th year as regards both future anxiety and self-efficacy crude scores using Student $t$ test: it is clear that that the mean score of self-efficacy and future anxiety of students in the 4th year is lower than students in the 1st year.

These findings have high statistical significance as per Student $t$ test ( $p$ value +0.001$)$

In Table 7, there is a strong inverse correlation between future anxiety and self-efficacy

\section{Discussion}

The present study reveals that there is a negative correlation between self-efficacy and future anxiety. It may due to the challenges that face the university students that include specialty selection, friends' choice, independence desire, exam stressors, fear of failure, residence in the University City and demands of the work field; all these challenges lead to variable levels of anxiety that often increase accompanied with a decrease in selfefficacy when the student realized disability to face these challenges This finding is supported by the findings of Sediek [14], whose study on 249 university students at Helwan University revealed that there is a negative relation between self-efficacy and future anxiety. This also agrees with Wylds [11] and Rauwaili [10].

The present study reveals that there is a negative significant correlation between the age and grade of students and self-efficacy; it may be due to the educational systems in Egypt play role in loss the student selfconfidence through the curriculum, and thus, the ability to reach the goal while there is a positive significant correlation between age of students and future anxiety. It may be due to the challenges, fear of the future, and pessimistic view increase with the age. The present study reveals that there was a significant increase in self-

Table 5 Comparing college type as regards both future anxiety and self-efficacy

\begin{tabular}{llllllll}
\hline & & Mean & S.D. & Min. & Max. & $F$ & $p$ \\
\hline Self-efficacy scale & Education & 115.98 & 127.89 & 13.68 & 65 & 150 & 47.64 \\
& Nursing & 117.71 & 11.17 & 104 & 148 & \\
& Total & 122.17126 .33122 .78 & 17.40 & 73 & 175 & 3.33 \\
Future anxiety scale & Education & & 18.78 & 93 & 191 & 0.069 \\
& Nursing & & 17.65 & 73 & 191 & \\
\hline
\end{tabular}


Table 6 Comparing grades (the 1st and 4th year) as regards both future anxiety and self-efficacy

\begin{tabular}{llllllll}
\hline & Grade & Mean & S.D. & Min. & Max. & $F$ & $p$ \\
\hline Self-efficacy scale & 1st & 119.80 & 14.19 & 65 & 150 & 16.720 & $.0001^{*}$ \\
& 4th & 114.56 & 13.07 & 85 & 148 & & \\
Future anxiety & Total & 117.71 & 13.98 & 65 & 150 & & \\
& 1st & 120.86 & 15.39 & 86 & 191 & 3.795 & $.05^{*}$ \\
Scale & 4th & 124.05 & 18.92 & 73 & 175 & & \\
\hline
\end{tabular}

efficacy in 1st year more than the 4th year in both students of nursing and education faculties. On the other hand, there is a significant increase in future anxiety in the 4th year more than the 1st year in both students of nursing and education faculties. It may be due to the students of the first academic year have an optimistic view of the life and power to maintain multiple goals while the students of the fourth academic year think about the future after graduation and the ability to face the community demands. In addition, the educational programs generally in Egypt cannot build students' ability to overcome the challenges and the curricula and give the students a limited chance to think about the future which does not match with the current work demands. These results agree with El-Mesykhey [8] who pointed out that there are a significant increase in future anxiety in the 4th year more than the 1st year in both students of science and literature faculties. On the other hand, there is a significant increase in self-efficacy in the 1 st year more than the 4th year in both students of science and literature faculties.

The present study revealed that there was a significant difference between the students of nursing and education faculties regarding the self-efficacy; students of nursing faculty show high self-efficacy more than the students of education faculty. It may be due to the fact that students in the practical colleges face challenges and solve the problems while working during the academic years of studying nursing. Study discipline in the theoretical colleges cannot offer a similar training atmosphere. The present study revealed that there was no significant difference between the students of nursing and education faculties regarding the future anxiety. It may due to the students of both theoretical and practical colleges live the same circumstances and challenges whether social, political, or economic. This makes many

Table 7 Correlation between age and both future anxiety scale and self-efficacy

\begin{tabular}{llll}
\hline & & Self-efficacy scale & Future anxiety scale \\
\hline Age & $r$ & $-.127-^{* *}$ & $.458^{*}$ \\
& $p$ & .005 & .02 \\
\hline
\end{tabular}

students suffer a decline in the level of optimism that leading to increase the symptoms of future anxiety. On a different line, Gaber [4] study, done on a sample of 81 students from Faculty of Education and Faculty of Engineering at Najran University, revealed that there is a significant statistical difference between the theoretical and scientific disciplines' students regarding future anxiety in the direction of theoretical disciplines' students. A third line is the research of Al-Momani \& Naeem [15], done on 439 college students in Al Jalil Region, revealed that there is no statistically significant difference regarding future anxiety among his sample. Further research is required to investigate these different findings and analyze the environmental role in these variations.

\section{Conclusion}

Further studies as regards the relationship between future anxiety and self-fficacy are required. Designing programs for developing the concept of self-efficacy on the basis of learning by modeling and reinforcing and putting therapeutic programs for future anxiety based on cognitive and emotional therapy is essential. Putting educational programs through the Ministry of Education to enhance self-efficacy and enriching the curriculum in all grades, especially university subjects contribute to raising levels of professional and academic ambition and help to reduce the level of future anxiety, can help. Organizing conferences through the Ministry of Higher Education to identify the social and economic problems of the youth and adopting set up debates, lectures, and opening chat channels with youth to create public awareness, is no luxury. Policy makers should be addressed to put future plans to identify the numbers admitted to the university according to the need of the Ministry of Higher Education to put an end to the problem of unemployment.

\section{Acknowledgements}

Not applicable

\section{Authors' contributions \\ SHR, SR, and NA contributed collaboratively in all steps of this research. Authors approval of manuscript: SHR, SR, and NA have read and approved} the manuscript.

\section{Funding}

this study was conducted on researchers' expense

Availability of data and materials

The datasets generated and analyzed during the current study are available.

Ethics approval and consent to participate

The study was approved by the ethics committee of Helwan University, meeting number 5 on the 2nd day of December 2015. The study participants gave written informed consent.

Consent for publication

Written informed consent to publish was taken from students participating in the study. 


\section{Competing interests}

There are no competing interests.

\section{Author details}

${ }^{1}$ Helwan University, Ain Helwan, Cairo, Egypt. ${ }^{2}$ Ain Shams University, Abbacia, Cairo, Egypt.

Received: 8 March 2020 Accepted: 30 July 2020

Published online: 18 September 2020

\section{References}

1. Yari, Bakht (2012) The relationship between self-efficacy and self 45 perception with anxiety of examination in high school students. Int J New Trends Educ Implications 3(4):59-66

2. Cheng F, Meng A, Yang L, Zhang Y (2013) The correlation between colostomy knowledge and self-care ability with psychosocial adjustment in Chinese patients with a permanent colostomy: a descriptive study. Colostomy Wound Manag 59(7):8-35

3. Syeda S, Ali A (2015) Religious faith, flourishing and general self-efficacy in young adults: a corrrelational study. Glob J Arts Hum Soc Sci 3(10):34-45

4. Gaber $\mathrm{OH}$ (2016a) Level of aspiration, critical thinking and future anxiety as predictors for the motivation to learn among a sample of students of Najran University, Najran University. Int J Educ Res 4:2

5. National Institution of Mental Health (2016) Anxiety disorders fact sheets. Department of Health and Human Services, USA

6. Almomani M, Naeem M (2013) Future anxiety college students in Al Jali region in light of some variable. Jordan J Educ Sci 9(2):173-185

7. Elmomani, M. \& Naim, N. (2013): The relationship between future anxiety and some variables for the community college students in the Galilee city, the Jordan J Educ Sci, 9, 2.

8. El-Meshekhy GM (2009) Future anxiety and its relation with self-efficacy and aspiration level among sample at El-Taif University Students, Doctorate Degree

9. Cassady JC (2010) Anxiety in the schools: the causes, consequences, and solutions for academic anxieties. Peter Lang, New York

10. Al Rauwaili M, Al Turki Y, Al Ardan A (2018) Social anxiety and its effects on self-efficay among family medicine resients in Riyadh. J Fam Med Prim Care 7(2):389-393

11. Wylds KR (2017). Role of self-efficacy and anxiety I resilience effects on performance and well-being. Wright state University, Masters of science

12. Mahmoued H (2013) Self-efficacy scale. Egyptian anglo library, Cairo

13. Abd el Tawab M, Abd el Azem S (2013) Future anxiety scale. Egyptian anglo library, Cairo

14. Sedik, M, A. (2012): Self-efficacy and future anxiety among university students, the psychological research center, Faculty of Arts, Cairo University.

15. Almomani M, Naeem M (2013) Future anxiety college students in Al-Jalil region in light of some variable. Jordan Journal of Education Sciences 9(2): 173-185.

\section{Publisher's Note}

Springer Nature remains neutral with regard to jurisdictional claims in published maps and institutional affiliations.

\section{Submit your manuscript to a SpringerOpen ${ }^{\circ}$ journal and benefit from:}

- Convenient online submission

- Rigorous peer review

- Open access: articles freely available online

- High visibility within the field

- Retaining the copyright to your article

Submit your next manuscript at $\boldsymbol{\nabla}$ springeropen.com 